\title{
DEBILIDADES EN LA EDICION DE J. SEGURA DE LOS «ELEMENTOS»DE WALRAS
}

\author{
CARLOS RODRIGUEZ BRAUN y \\ LUIS JULIAN ALVAREZ GONZALEZ \\ Universidad Complutense
}

Walras fue uno de los más grandes economistas de todos los tiempos. En consecuencia, la única actitud que cabe ante la traducción de sus Elementos de economía política pura es el alborozo, aunque haya mediado más de un siglo entre la primera edición del libro y la versión española.

La traducción puede parecer tardia, pero no lo es. Habrá que recordar la lenta historia de los Elementos, comenzando por el propio original, publicado originalmente en dos entregas, en 1874 y 1877 . En cuanto a traducciones, no las hubo hasta mediados de este siglo, y es destacable que la primera fue la japonesa de 1953. Después vinieron otras, al inglés, italiano y ahora al español, todas basadas en la llamada edición definitiva de 1926. Aún no existe una versión alemana.

En el caso de la flamante versión española de los Elementos, existe un motivo de regocijo adicional: el ingreso de Julio Segura en el campo de la historia del pensamiento económico, siguiendo una vieja tradición de los buenos economistas que, aquí y en el extranjero, gustan de bucear en lo orígenes de su disciplina.

Pero somos muchos los buzos y las profundidades prístinas son en ocasiones oscuras y misteriosas. No es de extrañar, por lo tanto, que choquemos unos con otros, ni que exploremos el mismo sitio y salgamos después a la superficie con relatos muy diversos acerca de lo que creemos haber visto.

Esto es lo que ha hecho Julio Segura. No se ha limitado al, en cualquier caso encomiable, esfuerzo de traducir a Walras sino que, actuando como un verdadero historiador de la ciencia, empleó su técnica moderna para abordar el pasado y extraer de él una interpretación personal. A raiz de ello, Carlos Rodríguez Braun entabló con él una polémica en esta Revista de Historia Económica 1 .

\footnotetext{
1 C. Rodriguez Braun y J. Segura, «Controversia a propósito de Walras», Revista de Historia Ecomómica, Año 6, n. 3, otoño 1988.
} 
No nos ocuparemos aqui, sin embargo, de cuestiones analíticas, sino principalmente de la labor de Julio Segura como traductor y de Alianza como casa editorial.

El que las traducciones económicas al español de la obras de los grandes economistas son insuficientes y manifiestamente mejorables no constituye secreto alguno ${ }^{2}$. Uno de los autores de la presente nota ha realizado un par de trabajos que demuestran empíricamente la validez de esa opinión negativa, vastamente extendida ${ }^{3}$.

¿Cómo es la traducción de los Elementos de Walras? En una palabra, aceptable. No obstante, como el panorama general de las traducciones es desolador, ello representa en realidad un elogio. La edición de Julio Segura, efectivamente, se halla por encima de la calidad media en España.

A continuación presentamos una lista de la debilidades de la traducción española. Igual que en su día hizo Carlos Rodríguez Braun con los Principios de Ricardo y la Teoria General de Keynes, no es una fe de erratas. En el terreno de las erratas y errores de escasa significación, los Elementos dejan muchísimo que desear. Hemos elaborado una extensa lista con unas 350 debilidades en un sentido muy lato, que remitimos en comunicación privada a Julio Segura para su utilización en una eventual segunda edición del libro y que está a disposición de los investigadores que la soliciten 4 .

El trabajo que presentamos aquí derivó del cotejo de tres ediciones de los Elementos de economia politica pura (la francesa, la inglesa y la española) ${ }^{5}$, y sólo aspira a evitar que el lector se pierda en otros laberintos que los estrictamente walrasianos.

${ }^{2}$ C. Rodriguez Braun, «Fuentes, traducciones y bibliografia en historia del pensamiento económicom, Documento de Trabajo 9005, Facultad de CC EE y Empresariales, Universidad Complutense, Madrid, 1990.

3 C. Rodriguez Braun, «Debilidades en la edición del Fondo de Cultura de los Principios de Ricardo* y «Debilidades en la edición del Fondo de Cultura de la Teoría General de Keynes», ambos publicados en Imvestigaciones Económicas, agosto 1982 y mayo 1986.

4 Los interesados pueden dirigirse a la atención de Carlos Rodriguez Braun, Hermanos García Noblej2s, 41, 28037 Madrid.

5 Los ejemplares confrontados fueron:

- L. Walras, Elementos de economía pura, edición y traducción de Julio Segura, Madrid, Alianza Editorial, 1987.

- L. Walras, Elements of pure economics, edición y traducción de William Jaffé, Filadelfia, Orion Editions, 1984 (reimpresión de la edición de Allen \& Unwin, 1954).

- L. Walras, Élements d"économie politique pure, edición de Pierre Dockés y otros, París, Economica, 1988 (corresponde al Volumen VIII de las Oenures Économiques Completes de Auguste y Léon Walras). 


\begin{tabular}{lll}
\hline Pág. & Lin. & Se lee \\
\hline 50 & 36 & el Paper de Jevons \\
50 & 40 & y la Pure Theory de Marshall \\
50 & 42 & $\begin{array}{l}\text { en } 1889 \text { el Kapital und Kapital- } \\
\text { zins }\end{array}$
\end{tabular}

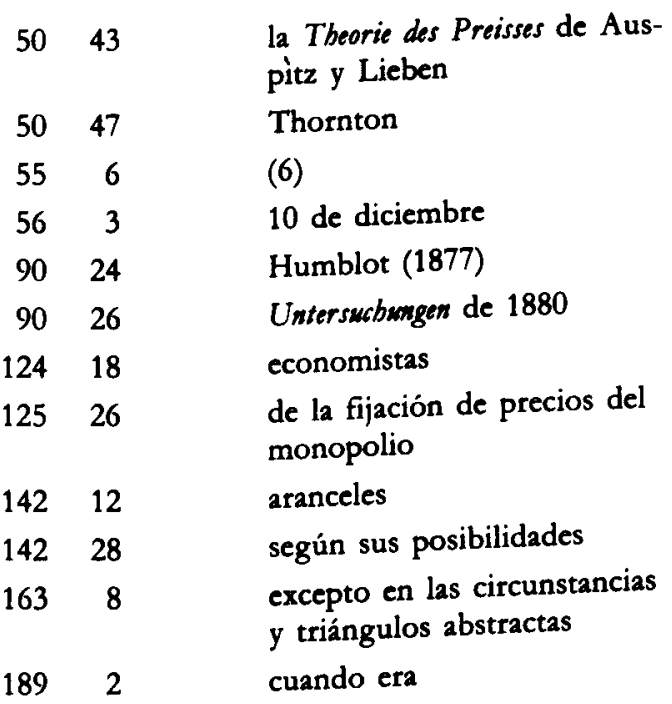
213 F.9 $p^{\prime}$
26239 tal y como las propias pala- bras austríaca y alemana indi- can

$274 \quad 11 \quad$ corrección no

$\begin{array}{lll}287 & 11 & (\text { A) } \\ 290 & 14 & m(m-1) \\ 303 & 10 & \begin{array}{l}\text { las condiciones de satisfac- } \\ \text { ción máxima de }\end{array}\end{array}$

\section{Debe leerse}

el «Brief account of a general mathematical theory of political economy" de Jevons

y la impresión privada, a cargo de Sidgwick, de los dos estudios sobre Pure Theory de Marshall

en 1884 el primer tomo del Kapital und Kapitalzins (en 1889 y 1921 los tomos segundo y tercero)

los Untersucbungen de Auspitz y Lieben

16 de diciembre

Humblot (1887)

Untersucbungen de 1889

fisiócratas

de la fijación de precios, del monopolio

precios intervenidos según lo que corresponde excepto en las circunferencias y triángulos abstractos cuando [como consecuencia del precio menor] era

P'

tal y como la emplean los austríacos y la propia palabra alemana indica

corrección, acaso por un olvido, no

(C)

\section{$m-1$}

las dos condiciones de satisfacción máxima y la de 
Pág. Lin. Se lee Debe leerse

31016 la utilidad de (B) del que re- la utilidad de (B), es decir, un sulta desplazamiento de la curva de necesidades, del que resulta

$\begin{array}{lll}311 & 39 & (10) \\ 324 & 6 & N \nu \\ 324 & 28 & \text { Supongamos ahora } \\ 334 & 26 & \text { y luego creciente } \\ 339 & 14 & \text { por desgracia } \\ 345 & \text { F.2a } & \text { RS } \\ 345 & 26 & \# 116 \\ 381 & 32 & \text { capitalista } \\ 388 & 18 & \text { al igual que } \\ 402 & 29 & p_{p} \\ 433 & 43 & \text { derivadas parciales son nulas }\end{array}$

(9)

$N \nu_{b}$

Hemos supuesto hasta aquí

y luego decreciente

por fortuna

RST

\#115

terrateniente

en vez de que lo hagan

$a_{p}$

derivadas parciales cruzadas son nulas

\begin{tabular}{|c|c|c|c|}
\hline 435 & 47 & pág. & pág. 751 \\
\hline 456 & 10 & $F_{c}$ & $F$ \\
\hline 456 & 11 & $F$ & $F$ \\
\hline 459 & 3 & $\phi_{d}\left(d_{d}\right)=p_{d} \phi_{d}\left(d_{d}\right)$ & $\phi_{(}\left(d_{d}\right)=p_{d} \phi_{d}\left(d_{d}\right)$ \\
\hline 460 & 21 & $F_{e}$ & $F$ \\
\hline 460 & 22 & $F$ & $F$, \\
\hline 460 & 28 & las cantidades de & $\begin{array}{l}\text { las cantidades, que suponemos } \\
\text { todavia constantes, de }\end{array}$ \\
\hline 470 & 13 & $D_{k^{\prime}}$ & $D_{k^{\prime}}^{\prime}$ \\
\hline 471 & 29 & $F$ & $F$ \\
\hline 472 & 23 & tiempo & tipo \\
\hline 476 & 4 & $i$ & $i "$ \\
\hline 484 & 5 & servicios de consumo & $\begin{array}{l}\text { servicios de los bienes de capital } \\
\text { nuevos }\end{array}$ \\
\hline 487 & 20 & cantidades empleadas & cantidades fabricadas \\
\hline 495 & 21 & $\begin{array}{l}\text { consideremos ahora tan sólo } \\
\text { para }\end{array}$ & podemos \\
\hline 502 & 6 & rentas netas & rentas brutas \\
\hline 538 & 15 & (d. & $\left(d_{a}\right)$ \\
\hline
\end{tabular}




Pág. Lin. Se lee Debe leerse

\begin{tabular}{|c|c|c|}
\hline $553 \quad 29$ & elevación o reducción & reducción o elevación \\
\hline 559 & El precio de (B) & El precio de $(\mathrm{O})$ \\
\hline 620 & $\begin{array}{l}\text { siendo una de las principales } \\
\text { operaciones crediticias }\end{array}$ & $\begin{array}{l}\text { siendo una de las principales las } \\
\text { operaciones crediticias }\end{array}$ \\
\hline 29 & progresión geométrica & progresión aritmética \\
\hline 25 & $b_{p} p_{b}$ & $b_{p}$ \\
\hline $672 \quad 25$ & por tanto & sin embargo \\
\hline 11 & $Q_{q}=q t$ & $O q=q t$ \\
\hline 21 & $\begin{array}{l}\text { no podemos discutir los efec- } \\
\text { tos de este fenómeno y su- } \\
\text { pondremos }\end{array}$ & $\begin{array}{l}\text { podemos no discutir los efectos } \\
\text { de este fenómeno y suponer }\end{array}$ \\
\hline $\begin{array}{l}\text { Gráfico } \\
\text { inferior } \\
\text { derecho }\end{array}$ & $\delta$ & $\delta^{\prime}$, \\
\hline $\begin{array}{l}\text { Gráfico } \\
\text { lado } \\
\text { izquierdo }\end{array}$ & $p_{a}, p_{b}, p_{i}, p_{d}$ & $\rho_{d}, \rho_{b}, \rho_{c}, \rho_{d}$ \\
\hline $\begin{array}{l}\text { Gráfico } \\
\text { superior } \\
\text { derecho }\end{array}$ & $p_{0}$ & P. \\
\hline 19 & ordenada & abscisa \\
\hline 38 & 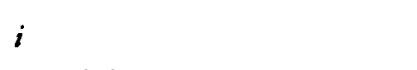 & $d p$ \\
\hline 24 & beneficio & \\
\hline
\end{tabular}

\section{COMENTARIOS ADICIONALES}

\section{Cuidar las formas}

La traducción de Julio Segura merece algunos reproches adicionales, en primer lugar por su falta de cuidado en las formas.

No hay virtualmente referencia alguna a las traducciones españolas, y muchas de las obras que menciona las tienen. Las citas y referencias adolecen en algunas oportunidades de una deplorable dejadez. Asi, por ejemplo, la nota 6 de la página 50 tiene un error cada dos líneas. 
En cuanto a las citas textuales, es de lamentar el criterio de no respetar el original de las citas de Jaffé de autores ingleses, y sí las escritas en francés o alemán. Habria sido aconsejable traducir todo, o bien respetar el original en todas las citas.

En algunas citas de autores antiguos se deberia haber tenido más cuidado y adaptar el texto a un español comprensible hoy. Tal es el caso, por ejemplo, de la cita de Say en las páginas 675-676, en las que existen muchas referencias a una "industria" que es, en realidad, "trabajo".

En la nota 21 de la página 52, sobre la acogida de las diversas ediciones de los Elementos, echamos de menos alguna mención a autores que publicaron comentarios sobre la obra, y que son figuras de interés, como G. F. Knapp, C. Gide y F. Simiand y A. Oncken. Asimismo, nos resulta extraña la mención que hace Segura, con respecto a la segunda edición de los Elementos de una "referencia anónima en el Journal of the Royal Statistical Society", que no recoge el completo listado del anexo I de la edición francesa. Podría tratarse, sin embargo, de una confusión con la lista de obras de economía matemática, que Jevons preparó para el Journal of the Statistical Society, pero antes, en 1878, y que envió a Walras. Jevons no firmó la lista pero su autoría es indisputable.

\section{E1 «liberalismo* clásico}

En cuanto a las interpretaciones de Julio Segura eludiremos, como hemos indicado más arriba, la cuestión más importante, que es su interpretación del caso del propio Walras, objeto ya de la referida polémica con Carlos Rodríguez Braun y en la que no deseamos entrar por el momento.

Existe, no obstante, una cuestión adyacente que no podemos dejar de señalar.

Dice Walras en la Lección 42, \#389:

Es cierto que una economía no podría funcionar sin la intervención de una autoridad encargada de mantener el orden y la seguridad, de administrar justicia, de garantizar la defensa nacional y de hacer muchas otras cosas más.

En este punto, y para destacar el carácter intervencionista de Walras, Julio Segura (pág. 805) subraya que Walras no se haya limitado a «la lista típica de los clásicos de policia-justicia-defensa», sino que ampliase el horizonte estatal hacia "muchas cosas más», entre las que Segura explicita los campos de la moneda, las condiciones de trabajo y otras. 
Aqui hay una gruesa equivocación, sólo justificable en la medida en que Julio Segura es un historiador todavía bisoño. Simplemente, no hay tal cosa como «la lista típica de los clásicos de policía-justicia-defensa». No existe tal lista. En el siglo clásico, de 1770 a 1870, desde el propio Adam Smith en adelante, los economistas admitieron e incluso exigieron un amplio abanico de posibilidades para la intervención de los poderes públicos en la vida económica.

Las obras públicas primero, por supuesto. Pero además toda clase de interferencias en el mercado monetario, las condiciones de trabajo, la navegación, las colonias, la tecnología, la educación, etc. Liberales sí, anarquistas no. $\mathrm{Y}$ además, de un liberalismo matizado.

Esto ha sido moneda corriente entre los historiadores del pensamiento económico durante muchos años y los grandes especialistas de este siglo lo han destacado una y otra vez, desde los trabajos ya clásicos de Viner y Robbins hasta los más modernos de O’Brien - recomendamos a este respecto el capítulo 10 de Los economistas clásicos de D. P. O’Brien (Madrid, Alianza, 1989).

En prueba cabal de lo que estamos diciendo, hacemos notar que los historiadores más liberales no titubean en censurar a los economistas clásicos precisamente por haber sido poco liberales (véase, p.ej., E. F. Paul, «El laissez faire en la Gran Bretaña del siglo XIX; ¿mito o realidad?», Libertas, V, 8, Buenos Aires, mayo 1988). 